\title{
Editorial
}

\section{Paying People to Be Healthy}

\author{
Evelyn L Forget ${ }^{\star}$ \\ Department of Community Health Sciences, University of Manitoba, Winnipeg, Manitoba, Canada
}

Received: 28 October 2013, Accepted: 12 November 2013, ePublished: 16 November 2013

\begin{abstract}
User Financial Incentives (UFIs) have emerged as a powerful tool for health promotion. Strong evidence suggests that large enough incentives paid to individuals conditional on behaviour they can control encourages more of the desired behaviour. However, such interventions can have unintended consequences for non-targeted behaviours. Implementation difficulties that result in individuals not understanding the nature of the incentive, unintended opportunities to "game" the system and inefficient roll-outs, can dampen results. Moreover, the legitimacy of paternalistic interventions by health planners requires careful consideration if we accept that the families involved will almost certainly be better judges of their own best interests than outsiders.
\end{abstract}

Keywords

Incentives, Behavioural Economics, Cash Transfers, User Financial Incentives, Health Promotion

A $s$ we struggle with the growing burden of chronic disease, "User Financial Incentives" (UFIs) are attracting international attention once again (1). Can we incentivize people to quit smoking or lose weight, for example, by offering them cash for desired outcomes? Are such policies as effective as or more effective than traditional health promotion policies? Are there unintended consequences?

Richard Thaler and Cass Sunstein introduced the language of "the nudge" (2)-shifting the choice architecture within which individuals make decisions-in 2008, but the idea of bribing individuals to behave well is as old as parenthood itself. In 2010, Time Magazine reported on a four-city experiment designed to determine whether paying children for good grades was effective. The experiment attracted positive responses from the children and somewhat less support from parents, but few people were indifferent. Apparently, the scientist behind the project received death threats (3). The mixed results of the randomized controlled experiment designed to test the effectiveness of the intervention suggest the complexity of the policy: kids did better when the incentives were paid for things children could directly control such as reading books or attending class, but less well when bribes were given for outcomes such as better grades over which the children receiving the incentive had only limited control (4). Similar results have been found elsewhere: in 2007, New York City (5) run an anti-poverty program on the basis of successes achieved in Mexico's Oportunidades Program (began as PROGRESA in 1997) and Brazil's Bolsa Familia Program (6). These Conditional Cash Transfer (CCT) schemes, since replicated elsewhere, showed that substantial improvements could be achieved in health and educational outcomes when payments to families are conditional on particular behaviours such as taking children to clinics or attending school. Overall, the New York City program showed that similar schemes could also lead to beneficial outcomes in wealthy countries such as the US; at least some improvements in children's educational outcomes in high school, parents' work efforts, savings and family health outcomes appeared early despite significant challenges associated with implementation. In the New York experiment, as in other cases, chaotic roll-outs left some participants uncertain about the details of the program and the expected behaviour.

The importance of carefully targeting the behaviour to be incentivized emerges in study after study. In Malawi, a randomized controlled experiment developed to encourage adolescent girls to attend school and achieve better grades was designed with two arms, as well as a control. In one arm, the families received cash transfers conditional on school attendance and in the second, they received an Unconditional Cash Transfer (UCT). Both the CCT and UCT encouraged school attendance relative to the control, but the CCT was much more effective (7). As in the New York experiment, it was easy to incentivize school attendance but performance was more difficult to affect. Nevertheless, in Malawi as elsewhere, a large enough payment, well understood and well directed, can encourage people to engage in more of the incentivized behaviour. Less direct goals of the intervention - performance on tests, for example, which are not a condition of payment-are less likely to be achieved. The most significant outcome of the Malawi experiment, however, is that a CCT conditional on educational behaviour might have other indirect effects, such as changing sexual behaviour and influencing health outcomes. Daughters of families in both the UCT and CCT arms were less likely to test positive for HIV and Herpes simplex than those in the control arm, even though sexual behaviour was not targeted (8). This finding raises significant questions about how targeting particular behaviours might affect outcomes.

The UCT arm was much less effective than the CCT arm

*Corresponding author: Evelyn L Forget; Email: Evelyn.Forget@med.umanitoba.ca 
at encouraging school attendance, which was the targeted behaviour. The CCT arm was also more cost-effective, both because the targeted behaviour was more prevalent among participants in this arm and because CCT families who did not meet the condition did not receive payments, while all the UCT families continued to receive payouts. The health outcomes, however, cast some additional light on the mechanism by which the cash transfers affect behaviour. When families receive a transfer conditional on daughters attending school, there is a strong incentive for families to ensure that the children do so. The poorest and most marginalized families, however, are less likely than others to react to the incentive by sending their daughters to school because families who face larger disincentives in the form of inadequate transportation or child care, for example, or greater reliance on child labour, need a greater "nudge" to overcome the barrier. For some, the bribe is simply not big enough to encourage them to educate their daughters. These poorest families will not receive payments if they are registered in the CCT arm, but will if they are in the UCT arm. What are the consequences for their daughters? The payment may not have been large enough for families to send these young women to school, but it could be large enough to serve as a barrier to early marriage or transactional sex. These are not targeted behaviours, but are desirable outcomes nonetheless. While these families would have been completely abandoned in the CCT arm, those in the UCT arm still benefit from the increased resources which they use in ways they perceive to be in their own best interests. The most vulnerable girls benefit most from UCTs, and benefit in ways not built as incentivized behaviour into the experiment (9).

The results of the Malawi experiment are significant because they suggest that not only must we be careful to target behaviour under the direct control of those who receive the payments, but that non-targeted behaviours might also be affected. This goes to the heart of the matter.

CCTs and UFIs are both aspects of what has been labelled liberal paternalism. While traditional development economics and much of the health promotion is overtly paternalistic, for example educational programs designed to change behaviour by addressing perceived misinformation about vaccination or laws to prevent undesirable behaviour such as smoking in public places, CTs and UFIs appear to allow individual families to make their own decisions-subject only to the "nudge" of the scientist. Like a tobacco taxes, these schemes represent just another price for a rational (or not) consumer to consider, as he or she ambles about optimizing outcomes subject to a variety of constraints.

The paternalism is, however, very real and carries with it the same sorts of threats and risks as other forms of paternalism. What if the scientists target the wrong outcome? We know from the educational interventions that targeting results rather than behaviours are less effective in generating desired outcomes, but it is the Malawi results that are most telling. Left to their own devices, individuals and families behave in ways that they believe will be in their own best interests. Given unconstrained resources in the form of UCTs, they will use the resources to pursue outcomes they believe will make them better off. The fact that many of the UCT families increased investment in their daughters' education suggests that their goals are different only in degree from those of the social planner. The better health outcomes achieved by the poorest families in the UCT arm simply suggest that, left to their own devices, families really do know how to best allocate their own resources in order to achieve their own goals. Their goals, however, may differ from those of the social planner.

Returning to the issues with which I began: can UFIs affect individual behaviour? Clearly, incentives can affect behaviour. If they target behaviours over which individuals have control, are large enough, are well understood by participants and are delivered in an efficient manner perceived to be just, they can have substantial effects on outcomes. Are such incentives as good as or better than traditional forms of health promotion? The jury is still out; comparative research does not exist. Might UFIs have unintended consequences? Human behaviour is complex. We ought to at least contemplate the possibility that individuals and families are not behaving as they do because they do not know any better. These families might indeed know better than the social planner what best interests them in their own. Paternalistic efforts to tamper with that decision making, by changing the choice architecture faces families deserve the same careful consideration as any other health intervention.

\section{Ethical issues}

Not applicable.

Competing interests

The author declares that she has no competing interests.

Author's contribution

ELF is the single author of the manuscript.

\section{References}

1. Oliver A, Lawrence D. Brown LD. A Consideration of User financial Incentives to address health inequalities. J Health Polit Policy Law 2012; 37: 201-26.

2. Thaler RH, Sunstein CR. Nudge: Improving decisions about health, wealth, and happiness. New Haven: Yale University Press; 2008.

3. Ripley A. Should kids be bribed to do well in school? Time Magazine [serial on the Internet]. [updated 2010 Apr 8; cited 2013 Nov 8]. Available from: http://content.time.com/time/magazine/ article/0,9171,1978758,00.html

4. Fryer RG Jr. Financial Incentives and Student Achievement: Evidence from Randomized Trials. Q J Econ 2011; 126: 1755-98.

5. Riccio JC. Early Findings from New York City's Conditional Cash Transfer program [internet]. 2010. Available from: http://www.irp. wisc.edu/publications/fastfocus/pdfs/FF5-2010.pdf

6. Paes-Sousa R, Santos LM, Miazaki ÉS. Effects of a conditional cash transfer programme on child nutrition in Brazil. Bull World Health Organ 2011; 89: 496-503.

7. Baird S, Mclntosh C, Özler B. Cash or condition? evidence from a cash transfer experiment. Q J Econ 2011; 126: 1709-53.

8. SJ Baird, RS Garfein, CT McIntosh, B Özler. Effect of a cash transfer programme for schooling on prevalence of HIV and herpes simplex type 2 in Malawi: a cluster randomised trial. Lancet 2012; 379: 1320-9.

9. Horwitz JR, Kelly BD, DiNardo JE. Wellness incentives in the workplace: cost savings through cost shifting to unhealthy workers. Health Aff (Millwood) 2013; 32: 468-76. 